\title{
RUPTURED CORNUAL PREGNANCY AT 8 WKS GESTATION- SUCCESSFUL CONSERVATIVE APPROACH: A CASE REPORT
}

Shakun Singh ${ }^{1}$, Pratima Verma ${ }^{2}$, Anamika ${ }^{3}$, Nishat ${ }^{4}$

\section{HOW TO CITE THIS ARTICLE:}

Shakun Singh, Pratima Verma, Anamika, Nishat. "Ruptured Cornual Pregnancy at 8 Wks Gestation- Successful Conservative Approach: A Case Report". Journal of Evolution of Medical and Dental Sciences 2014; Vol. 3, Issue 59, Nov 06; Page: 13347-13349, DOI: 10.14260/jemds/2014/3779

\begin{abstract}
Cornual pregnancy is a rare form of ectopic pregnancy that usually lead to uterine rupture with resultant life threatening haemorrhage. The mortality of interstitial pregnancy is more than twice than that of other tubal pregnancies. Cornual pregnancy usually rupture later than other tubal pregnancies because the myometrium is more distensible than the fallopian tube. We report a case where a patient presented at 8 weeks of gestational age with ruptured cornual ectopic pregnancy and haemoperitoneum. Emergency laprotomy was done and cornual rupture was sutured successfully.
\end{abstract}

KEYWORDS: Cornual Ectopic preg, laprotomy.

INTRODUCTION: The interestitial part of the fallopian tube is the proximal portion that lies within the muscular wall of the uterus. It is $0.7 \mathrm{~mm}$ wide and approx. $1-2 \mathrm{~cm}$ long with a slightly tortuous course extending obliquely upwards and outwards from the uterine cavity. Pregnancies implanted on this site are called as interstitial or cornual pregnancies. Cornual pregnancies account for $2-4 \%$ of ectopic pregnancies \& have $2-2.5 \%$ mortality risk. Cornual gestation is one of the most hazardous type of ectopic gestation which may often require hysterectomy. Risk factors are as for other type of ectopic pregnancies eg. Contralateral salpingectomy previous ectopic pregnancy, smoking, IUCD and progesterone only pills, in utero DES exposure, increasing age. Until recently, cornual ectopic or interstitial pregnancies have been treated by laprotomy with cornual excision or hysterectomy. But recently now attempts have been made for conservative approach where cornual repair in being done.

CASE REPORT: A 30 year old $\mathrm{G}_{3} \mathrm{P}_{2} \mathrm{~L}_{2}$ presented to labour room with the complaint of amenorrhoea of one and half month, weakness, pain in lower abdomen since 1 day. She has done her urine pregnancy test which was positive.

Per abdominal examination revealed severe tenderness in lower abdomen with positive shifting dullness. Pelvic examination revealed severe tenderness in left fornix, uterus was soft, retroverted cervical motion tenderness was present. Emergency USG was done which showed A heterogenous area with fluid and products of size $95 \times 74 \times 39 \mathrm{~mm}$ and volume $149 \mathrm{cc}$ in left adenexa? Ruptured ectopic pregnancy.

Findings were suggestive of ruptured ectopic pregnancy. Her immediate laboratory test included $\mathrm{Hb}-4$ gms\%, BT/CT within normal limits. Blood group B positive\& HIV \& HBsAg Negative. Past obstetric H/o Full term normal vaginal delivery.

Consent was taken for emergency laparotomy and 2 unit blood was arranged. Emergency laprotomy was done. About $2000 \mathrm{ml}$ of blood was present in abdominal cavity with 250 gms of blood clots. Ruptured left cornual ectopic seen with bilateral tubes and ovaries normal (Fig.1) 


\section{CASE REPORT}

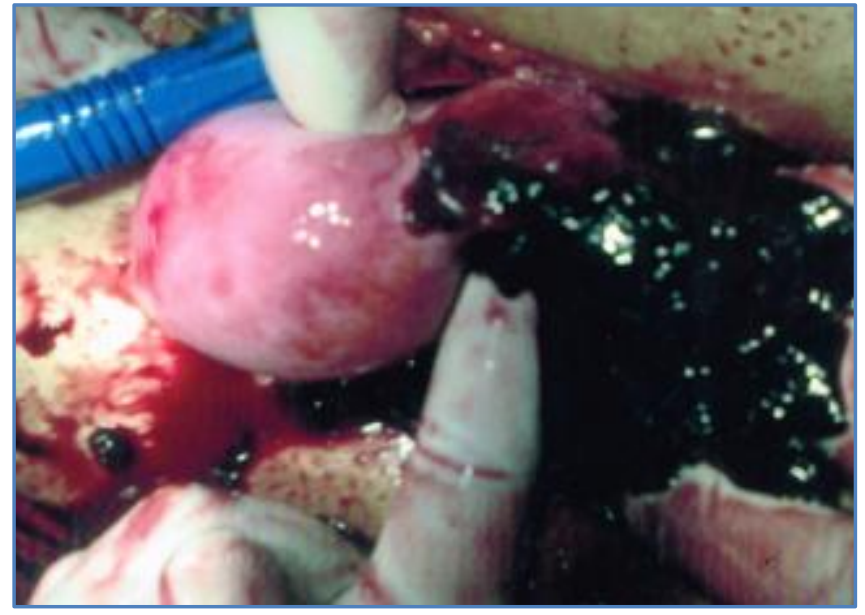

Figure 1

Cornual repair was done with vicryl no. 1. Haemostasis attained and instruments and mop counted. Abdominal wall was closed in layers. Postoperatively, 3 units of blood was transfused. Postoperative course was uneventful and she was discharged on 7 day in good condition.

DISCUSSION: Cornual pregnancy is diagnosed with ultrasonographical criteria in presence of positive hCG indicating pregnancy. These criteria include:

1. An empty uterus

2. A gestational sac seen separately and $>1 \mathrm{~cm}$ from the most lateral edge of uterine cavity

3. A thin myometrial layer surrounding the sac.

A thin echogenic line extends into the cornual region abutting the gestational sac and this is called "The interstitial line sign". The interstitial line can be either the endometrial cavity or the interstitial portion of the fallopian tube. Early diagnosis of cornual pregnancy with TVS allows for first trimester conservative management with methotrexate.

Tulandi et al reviewed the management of 32 reported cases of cornual pregnancy. Ultrasound revealed an ectopic cornual gestation sac in $40.6 \%$ and a hyperechoic area/ mass in the cornual region in another $25 \%$. The diagnosis was established in $71.4 \%$ of 32 woman with sensitivity of $80 \%$ and specificity of $99 \%$. 4D volume contrast imaging can differentiate between angular and cornual pregnancy. In Angular pregnancy embryo is implanted medial to uterotubal junction and round ligament while in cornual pregnancy embryo is implanted lateral to round ligament.

Pehsson et al reported a case of uterine cornual rupture following attempted mid trimester induced abortion for presumed intra-uterine pregnancy. They stated that physicians should consider pregnancy when attempts at induced abortions do not succeed.

Traditionally, the treatment of cornual pregnancy has been hysterectomy or cornual resection at laparotomy. As all surgical management has been associated with morbidity and unfavorable effects on fertility, more conservative approaches have been introduced into practice. Conservative techniques such as laproscopic cornual resection, laproscopic cornuostomy or hysteroscopic removal of interestitial ectopic tissue, unilateral uterine artery ligation have been tried. 
Medical methods such as systemic methotrexate in safe and highly effective treatment for cornual pregnancy so that surgery can be avoided if detected early.

Presentation at a relatively early gestation with cornual rupture, haemostasis can be obtained by just repairing the ruptured area. Early diagnosis added by USG or laparoscopy may help to contribute towards effective conservative management.

\section{REFERENCES:}

1. Submyomatous cornual pregnancy: Managed surgically after failed medical management. L Al Kharusi, V Gauri,R Al-Sukarti-Sultan Qaboos,2011- ncbi.nlm.nih.gov

2. Ruptured cornual monochorionic monoamniotic twin ectopic pregnancy- A case report. B T Utoo,S O Ojo-Jos Journal of Medicine,2011-ajol.info.

3. Recurrent cornual pregnancy successfully treated with methotrexate, following a ruptured pregnancy in the contralateral cornu. A Fabre-Gray, M Read, P Wardle- Journal of obstetrics \& Gynae 2014- informahealthcare.com.

4. Ruptured cornual pregnancy- A case report. T Takei, S Matsuoka, N Ashitani ,Makihara N, Morizane M, Ohara N.

5. Clinical and Experimental Obstetrics \& Gynae (2009, 36 (2):130-132).

\section{AUTHORS:}

1. Shakun Singh

2. Pratima Verma

3. Anamika

4. Nishat

\section{PARTICULARS OF CONTRIBUTORS:}

1. Associate Professor, Department of Obstetrics and Gynaecology, LLRM Medical College, Meerut, Uttar Pradesh.

2. Junior Resident III, Department of Obstetrics and Gynaecology, LLRM Medical College, Meerut, Uttar Pradesh.

3. Junior Resident II, Department of Obstetrics and Gynaecology, LLRM Medical College, Meerut, Uttar Pradesh.
4. Junior Resident II, Department of Obstetrics and Gynaecology, LLRM Medical College, Meerut, Uttar Pradesh.

\section{NAME ADDRESS EMAIL ID OF THE CORRESPONDING AUTHOR:}

Dr. Shakun Singh,

\#R-2, LLRM Medical College Campus, Meerut, Uttar Pradesh.

E-mail: singhshakun77@gmail.com

Date of Submission: 20/04/2014.

Date of Peer Review: 21/04/2014.

Date of Acceptance: 29/04/2014.

Date of Publishing: 06/11/2014. 